\title{
Genetic Construction of Truncated and Chimeric Metalloproteins Derived from the $\alpha$ Subunit of Acetyl-CoA Synthase from Clostridium thermoaceticum
}

\author{
Huay-Keng Loke, Xiangshi Tan, Paul A. Lindahl* \\ Contribution from the Departments of Chemistry and of Biochemistry and Biophysics, \\ Texas A\&M University, College Station, TX 77843 \\ RECEIVED DATE (will be automatically inserted after manuscript is accepted)
}

A common strategy for analyzing the active sites of metalloenzymes is to synthesize coordination complexes that have structures and/or reactivity properties related to but simpler than the actual site. Polypeptide ligands are increasingly used in such endeavors, as the resulting metallopeptides (also called maquettes) are water-soluble and have proteinaceous secondary spheres that mimic metalloprotein environments. Moreover, polypeptide scaffolds are suitable for building complex systems with multiple metal centers, distorted geometries, as well as regulatory and cooperative properties. Amino acid sequences used in synthesizing metallopeptides are generally selected by socalled rational design methods. These methods use computational algorithms that consider physical/chemical properties of proteins in aqueous solution, as well as consensus sequences of target metal-binding regions or of proteins with desirable secondary structures. ${ }^{1-4}$ DeGrado used such a de novo design approach to construct a metallopeptide model of the dinuclear Fe-oxo site of ribonucleotide reductase. ${ }^{5}$ Polypeptide helices incorporating hemes and $\mathrm{Zn}$ ions have also been synthesized in this manner. ${ }^{4,6-11}$ Imperiali and coworkers have constructed sophisticated $\mathrm{Zn}$ and $\mathrm{Cu}$ metallopeptides that function as chemosensors. ${ }^{12-15}$ Gibney and Dutton utilized the consensus sequence of ferredoxins to build $\mathrm{Fe}_{4} \mathrm{~S}_{4}$-cluster-coordinating polypeptides that are redox active and exhibit characteristic EPR signals. ${ }^{2,3}$ Holm and Laplaza used polypeptides as scaffolds to assemble $\mathrm{Fe}_{4} \mathrm{~S}_{4}$ clusters in close proximity to Ni centers, with the aim of modeling the A-cluster of acetyl-Coenzyme A synthase (ACS). ${ }^{16}$ This center has also been modeled by Holm, Riordan, Sellmann, and Pohl using nonproteinaceous ligands. ${ }^{17-20}$ Although such constructs are catalytically inactive and lack the precise spectroscopic, redox, and substrate-binding characteristics of the A-cluster, they each represent outstanding progress towards this difficult modeling goal.

A related approach, known as "redesign", alters existing protein structures by adding/modifying metal centers and/or regulatory elements. Caradonna et al. used the DEZYMER algorithm to incorporate an $\mathrm{Fe}_{4} \mathrm{~S}_{4}$ synthetic cluster within the protein matrix of thioredoxin. ${ }^{21,22}$ This resulted in a redox-active high potential iron-sulfur protein (HiPIP). Similar approaches were used to synthesize a functional rubredoxin ${ }^{23}$ and a catalytic Fe-superoxide dismutase (Fe-SOD). ${ }^{24} \mathrm{Lu}$ and coworkers introduced a $\mathrm{Cu}_{\mathrm{B}}$ center into both sperm whale myoglobin and cytochrome $c$ peroxidase, thus successfully engineering hemecopper oxidases. $^{25,26}$ Much progress have also been made in redesigning heme and non-heme iron proteins. ${ }^{27}$

The difficulties involved in modeling the active sites of complex metalloenzymes such as the A-cluster of ACS can be gauged from a description of the natural system. ACS from Clostridium thermoaceticum is a $310 \mathrm{kda}$ protein that catalyzes two reactions, including the reversible reduction of $\mathrm{CO}_{2}$ to $\mathrm{CO}$ and the synthesis of acetyl-CoA from $\mathrm{CO}, \mathrm{CoA}$, and a methyl group transferred from a corrinoid-iron sulfur protein $(\mathrm{CoFeSP}){ }^{28}$ ACS contains two novel Ni-Fe-S clusters (the A- and C-clusters) connected by a molecular tunnel through which $\mathrm{CO}$ migrates. The enzyme is an $\alpha_{2} \beta_{2}$ tetramer in which the A-cluster is located in the $\alpha$ subunit and the C-cluster (along with two types of $\mathrm{Fe}_{4} \mathrm{~S}_{4}$ clusters) is located in $\beta .^{29,30}$ The A-cluster appears to consist of a $\mathrm{Ni}$ complex bridged to an $\mathrm{Fe}_{4} \mathrm{~S}_{4}$ cluster. The UV-vis spectrum of the A-cluster exhibits broad absorption in the $400 \mathrm{~nm}$ region, typical of $\mathrm{Fe}_{4} \mathrm{~S}_{4}$ clusters. The diamagnetic oxidized cluster $\left(\mathrm{A}_{\mathrm{ox}}\right)$ can be reduced by one electron and bound with $\mathrm{CO}$, yielding an $\mathrm{S}$ $=1 / 2$ state called $\mathrm{A}_{\text {red }} \mathrm{CO}$. This state affords a near-axial NiFeC EPR signal with $\mathrm{g}=2.08,2.07$, and 2.03. A combined EPR/Mössbauer study concluded that $\mathrm{A}_{\mathrm{ox}}$ and $\mathrm{A}_{\text {red }}-\mathrm{CO}$ correspond to $\left[\mathrm{Fe}_{4} \mathrm{~S}_{4}\right]^{2+}-\mathrm{X}-\mathrm{Ni}^{2+}$ and $\left[\mathrm{Fe}_{4} \mathrm{~S}_{4}\right]^{2+}-\mathrm{X}-\mathrm{Ni}^{1+}-\mathrm{CO}$, respectively. ${ }^{31}$ The intensity of the $\mathrm{NiFeC}$ signal quantifies to only $0.2-0.4$ spins $/ \alpha$, the result of heterogeneous populations of A-clusters. The form of the A-cluster that exhibits this signal, called Ni-labile, is catalytically active and has a Ni ion that can be removed by treatment with 1,10-phenanthroline (phen). ${ }^{32-34}$ The resulting catalytically inactive phen-treated ACS is reactivated upon incubation with $\mathrm{NiCl}_{2}$. The other form of the A-cluster (called Nonlabile) is catalytically inactive and contains $\mathrm{Ni}$ ions insusceptible to phen treatment. The exact coordination environment of the $\mathrm{Ni}$ is not known, but it appears to consist of $2 \mathrm{~S}$ and $\sim 2 \mathrm{~N}$ donors (from cysteine and histidine residues), organized in a geometry that leaves two open cis coordination sites. ${ }^{35,36}$ These sites are thought to bind $\mathrm{CO}$ and a methyl group during catalysis. $^{28,29}$ A hypothetical redox-active cystine/cysteine disulfide/dithiol called the D-site may facilitate methyl group transfer. The $\mathrm{Ni}^{2+}$ ion may receive an electron-pair from this site as the methyl cation binds. ${ }^{36}$ Then, $\mathrm{CO}$ binds the resulting methylbound $\mathrm{Ni}$, followed by $\mathrm{CO}$-insertion into the $\mathrm{Ni}^{2+}-\mathrm{CH}_{3}$ bond. Finally, $\mathrm{CoA}$ attacks $\mathrm{Ni}^{2+}-\mathrm{C}(\mathrm{O}) \mathrm{CH}_{3}$ yielding the product acetylCoA.

Advances in molecular genetics now permit genes that encode cloned metalloproteins to be manipulated in a highly flexible manner, and for various purposes. For example, the binding and catalytic domains of sulfite reductase and methionine synthase have been investigated by truncation methods. ${ }^{37-39}$ The $\beta$ subunits of $\alpha_{8} \beta_{4}$ sulfite reductase contain a siroheme coupled to an $\mathrm{Fe}_{4} \mathrm{~S}_{4}$ cluster. Isolated $\beta$ subunits are catalytically active in the absence of $\alpha$ as long as NADPH is replaced with an $n=1$ reductant. $^{37}$ Truncated forms of the $\alpha$ subunit revealed FAD and FMN binding sites. ${ }^{38}$ When exogenous cobalamin is included in assays, a truncated form of methionine synthase retains the catalytic activity of native enzyme. ${ }^{39} \mathrm{In}$ addition, the $\mathrm{Cu}_{\mathrm{A}}$-containing $\mathrm{C}$ terminal domain of subunit II of cytochrome $\mathrm{c}$ oxidase was generated using genetic truncation, thus allowing spectroscopic analysis of the dimeric $\mathrm{Cu}_{\mathrm{A}}$ site. ${ }^{40-42}$ 
We recently cloned the genes encoding ACS and obtained active recombinant enzyme by overexpression in Escherichia coli. ${ }^{43}$ Intrigued by efforts made to synthesize metallopeptides and complexes that model the A-cluster, we endeavored to prepare truncated A-cluster-containing proteins using the molecular genetic approach. In this paper, we report the preparation and characterization of three metalloproteins derived from ACS in which the region responsible for A-clustercoordination was retained while other apparently superfluous regions of native enzyme were eliminated. We illustrate an advantage of this approach, by constructing chimeras in which the ferredoxin from Chromatium vinosum was fused to these truncation products, creating new metalloproteins with multiple metal centers and unanticipated properties.

\section{Experimental Section}

Materials. Restriction enzymes AflIII, BglII, HindIII, NcoI, NdeI, and XhoI were purchased from New England Biolabs. T4 DNA ligase and isopropylthio- $\beta$-D-galactosidase (IPTG) were from Promega. Pfu Turbo polymerase and E. coli strain XL1-Blue were from Stratagene. Vector pQE-60, Ni-nitrilotriacetic acid (Ni-NTA) agarose, QiaPrep Spin Miniprep Kit, and QIAquick PCR Purification Kit were from Qiagen, while vector pET23b was from Novagen. The following oligonucleotide pimer pairs, labeled P1 - P8, were synthesized by the Gene Technologies Laboratory (GTL) in the Department of Biology at Texas A\&M University:

P1 (5'-GGCGGACATGTCTGATTTTGATAAAATC-3', 5'GGCGGAGATCTCATAATGGGATCCATGG-3'); P2 (5'-GGCGGCTCGAGGGATCCACGCGGAACCA GAGATCTCATAATGGG-3', 5'GGCGGCATATGATCAAGCTCACCAA G-3'); P3 (5'-GGCGGCATATGGAAGGAGTCCTCGAACGG-3', 5'GGCGGCTCGAGGGATCCACGCGGAACCAGCTCCGGC AGGATGGC-3'); P4 (5'-GGCGGCCATGGCCCTGATGATTACCG-3', 5'GGCGGAGATCTGCCTTCGCCGGTGATGCG-3'); P5 (5'-GGCGGCTCGAGGGATCCACGCGGAACCAGAGATC TCATA-3', 5'-GGCGGAAGCTTACTGATTTTGATAAAATCT TCG-3');

P6 (5'-GGCGGCATATGGCCCTGATGATTACCG-3', 5'GGCGGAAGCTTGCCTTCGCCGGTGATGCG-3'); P7 (5'-GGCGGACATGTCCCTGATGATTACCG-3', 5'GGCGGAGATCTCATAATGGGATCCATGG-3'); and P8 (5'-GGCGGAAGCTTATCAAGCTCACCAAGATC-3', 5'GGCGGCTCGAGGGATCCACGCGGAACCAGAGATCTCAT A-3').

Subcloning of $\operatorname{acs} B 1$, $\operatorname{acs} B 2$, and $\operatorname{acs} B 3$. Gene fragments $a c s B 1$ (encoding AcsB residues 1 - 729), acsB2 (encoding residues $311-729$ ), and $a c s B 3$ (encoding residues $400-607)^{44}$ were amplified from $\mathrm{pTM} 02^{43}$ using Pfu Turbo polymerase, dNTPs (Invitrogen), a thermocycler (MJ Research Minicycler ${ }^{\mathrm{TM}}$ ) and $\mathrm{P} 1, \mathrm{P} 2$, and $\mathrm{P} 3$, respectively. $\mathrm{PCR}$ products $(2.2,1.3$, and 0.6 $\mathrm{kb})$ were purified with the QIAquick PCR Purification Kit. acsB1 was digested with $A f l I I I$ and $B g l I I$, and subsequently ligated with T4 DNA ligase to linearized pQE-60 that had been digested with NcoI and BglII. acsB2 and acsB3 were both digested with NdeI and XhoI and then ligated to linearized pET23b that had been similarly digested. Ligation mixtures were transformed into XL1Blue cells. Plasmids pLHK05, pLHK07, and pLHK10 were isolated from ampicillin-resistant cells. Residues W419, R424, I556, T566, and Q574 of pLHK10 were changed to M419, D424, D556, E566, and E574, respectively, using QuikChange ${ }^{\mathrm{TM}}$ Site-
Directed Mutagenesis Kit (Stratagene), yielding acsB3' in pEH05.

Subcloning of $\boldsymbol{f} d \boldsymbol{x}$. $\quad f d x$ was similarly amplified from pCVFD $10^{45}$ using primers $\mathrm{P} 4$ under conditions described above. The resulting $0.3 \mathrm{~kb}$ PCR product was purified with the QIAquick PCR Purification Kit and subsequently digested with NcoI and BglII. The digested PCR product was ligated with similarly digested pQE-60 and transformed into E. coli XL-1 Blue cells. Vector $\mathrm{pQF} 1$ was isolated from ampicillin-resistant cells.

Subcloning of $\boldsymbol{f} \boldsymbol{d} \boldsymbol{x}$-acsB $\mathbf{1}$ '. acsB1' (encoding AcsB residues 2 - 729) was amplified from pTM02 using primers P5 and $f d x$ from vector pCVFD10 using primers $\mathrm{P} 6$, resulting in PCR products of 2.2 and $0.3 \mathrm{~kb}$ 's, respectively in lengths which were purified. PCR product of acsB1' and vector pET23b were digested with HindIII and XhoI, and subsequently ligated together. The ligation mixture was transformed into E. coli XL-1 Blue cells and pETB1 was isolated from ampicillin-resistant cells. pETB1 and PCR product of $f d x$ were digested with $N d e I$ and HindIII, ligated together and transformed into XL-1 Blue cells. Vector pETR81 containing a fusion of both the $f d x$ and $a c s B 1$ ' genes was isolated from ampicillin-resistant cells. pETR1 was then used as a template to amplify the gene-fusion with primers P7. The PCR product of $1.6 \mathrm{~kb}$ was digested with $A f l I I I$ and $B g l I I$ and ligated to linearized pQE-60 (digested with $N c o I$ and BglII). The resulting ligation mixture was transformed into XL-1 Blue cells and vector pAF81 was isolated from cells resistant to ampicillin.

Subcloning of $\boldsymbol{f} \boldsymbol{d} \boldsymbol{x}$-acsB2'. acsB2' (encoding AcsB residues 312 - 729) was amplified from pTM02 using primers P8. $f d x$ was similarly amplified from vector pCVFD10 using primers P6. Resulting PCR products of 1.3 and $0.3 \mathrm{~kb}$ 's, respectively, were purified. Vector pET23b and the PCR product of acsB2' were digested with HindIII and XhoI, and subsequently ligated together. The ligation mixture was transformed into $E$. coli XL-1 Blue cells, and pETC1 was isolated from ampicillin-resistant cells. pETC1 and the PCR product of $f d x$ were digested with NdeI and HindIII, ligated together and transformed into XL-1 Blue cells. Vector pETR51 containing a fusion of both the $f d x$ and acs $B 2$ ' genes was isolated from ampicillin-resistant cells. pETR51 was subsequently used as a template to amplify the gene-fusion with primers P7. The $1.6 \mathrm{~kb}$ PCR product was digested with AflIII and BglII and ligated to linearized pQE-60 (digested with $\mathrm{NcOI}$ and $\mathrm{BglII}$ ). The resulting ligation mixture was transformed into XL-1 Blue cells and vector pAF51 was isolated from ampicllin-resistant cells.

Expression of $a \operatorname{cs} B 1, a c s B 2, a c s B 3, f d x, f d x-a c s B 1$, and $f d x$ acsB2'. $a \operatorname{cs} B 1, f d x, f d x$ - $a c s B 1$ ', and $f d x$ - $a \operatorname{cs} B 2$ ' were expressed in E. coli strain JM109 (Stratagene), while acsB2 and acsB3' were expressed in BL21(DE3) (Pharmacia). JM109 (pLHK05), JM109 (pAF51), JM109 (pAF81) and BL21(DE3) (pLHK07) cells were grown in $25 \mathrm{~L}$ of Begg's media at $37^{\circ} \mathrm{C}$ under anaerobic conditions, induced with $0.1 \mathrm{mM}$ IPTG and $0.5 \mathrm{mM} \mathrm{NiCl}_{2}{ }^{43}$ harvested anaerobically and frozen in liquid $\mathrm{N}_{2}$. JM109 (pQF1) was similarly grown and harvested under anaerobic conditions but induced with $0.1 \mathrm{mM}$ IPTG. BL21(DE3) (pEH05) cells were grown in $25 \mathrm{~L}$ of Luria Bertani (LB) broth at $37^{\circ} \mathrm{C}$ under aerobic conditions, cooled to $15^{\circ} \mathrm{C}$ prior to induction with both IPTG and $\mathrm{NiCl}_{2}$, harvested aerobically, and frozen.

Purifications and Characterizations of Ferredoxin and of Truncated and Chimeric Proteins. Expression of $f d x, a c s B 1$, $a \operatorname{cs} B 2, a c s B 3$ ', $f d x$ - $a \operatorname{cs} B 1$ ', and $f d x$ - $a \operatorname{cs} B 2$ ' yielded Fd, $\alpha_{82}, \alpha_{49}$, $\alpha_{23}, \alpha_{82}-\mathrm{Fd}$, and $\alpha_{49}-\mathrm{Fd}$, respectively. These proteins were fused to His-tags, allowing anaerobic purification with $\mathrm{Ni}^{-\mathrm{NTA}^{43}}$ and DEAE columns with a $0.1-0.4 \mathrm{M} \mathrm{NaCl}$ gradient in Tris-Cl buffer, $\mathrm{pH}$ 8.0. Protein purities, concentrations, $\mathrm{Ni}$ and $\mathrm{Fe}$ 
contents, UV-vis and EPR spectra were determined as described, 43 except that the samples of the ferredoxin and chimeric proteins were acquired using a Bruker EMX EPR spectrometer. Using anaerobic procedures, samples were oxidized by adding thionin until $\mathrm{Abs}_{600}$, due to oxidized thionin, increased. Samples were reduced by adding sodium dithionite until $\mathrm{Abs}_{420}$ ceased declining. Samples were activated by passage through a column of Sephadex G-25 (1 cm X $17 \mathrm{~cm})$ equilibrated in $50 \mathrm{mM}$ MOPS $\mathrm{pH} 7.5$, oxidized with 1 equiv./mol of thionin, and incubated $4 \mathrm{hr}$ in 5 equiv. $/ \mathrm{mol} \mathrm{NiCl}_{2}$ under $\mathrm{Ar}$ at room temperature. Activated samples analyzed by EPR were freed of thionin and $\mathrm{NiCl}_{2}$ by Sephadex G-25 chromatography prior to addition of dithionite and $1 \mathrm{~atm} \mathrm{CO}$.

Acetyl-CoA Synthase Assay. Assays were performed as described, ${ }^{46,47}$ except that $\mathrm{CH}_{3}$-THF and Coenzyme A stock solutions were $36 \mathrm{mM}$ and $34 \mathrm{mM}$, respectively, CO (MG Industries, Research Grade) was used in place of $\mathrm{CO}_{2}$, the $\alpha$ subunit (final concentration, $2.0 \mu \mathrm{M}$ ) was used in place of ACS, and $50 \mu \mathrm{L}$ (rather than $20 \mu \mathrm{L}$ ) aliquots were withdrawn for HPLC analysis.

\section{Results}

Biosynthesis and Characterization of Truncated Metalloproteins. Our initial goal was to correlate the extent to which native ACS could be truncated while maintaining characteristic properties of the A-cluster. Previous studies had shown that the $\alpha$ subunit is stable when isolated from $\beta$, and so the gene encoding just the $82 \mathrm{kda} \alpha$ subunit was cloned and overexpressed in E. coli. The resulting protein will be referred to as $\alpha_{82}$. All 6 conserved cysteines and 3 conserved histidine residues of the $\alpha$ subunit from $C$. thermoaceticum are located within a $\sim 50 \mathrm{kda}$ region of this subunit. Also, the remaining $\sim 30$ kda region, located at the $\mathrm{N}$ terminus of the $C$. thermoaceticum subunit, is absent in homologous subunits from some other ACS enzymes. ${ }^{48}$ These facts suggested that the latter region could be deleted genetically without destroying the A-cluster. The resulting recombinant protein will be called $\alpha_{49}$. Finally, additional regions on either side of the conserved sequences were deleted, resulting in a truncated protein $\left(\alpha_{23}\right)$ that contained 8 of the 9 conserved $\mathrm{Cys} / \mathrm{His}$ residues (a conserved His residue was sacrificed to allow for more extensive truncation). These modifications are illustrated in Figure 1.

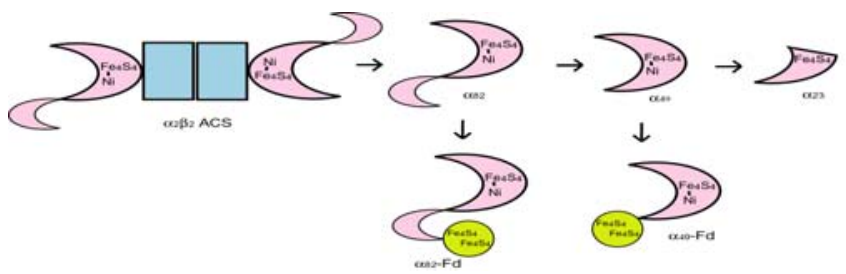

Figure 1. Summary of genetic truncations and fusions described in this study. Native $\alpha_{2} \beta_{2}$ ACS (top left) was truncated progressively to $\alpha_{82}, \alpha_{49}$, and $\alpha_{23}$. Ferredoxin from Chromatium vinosum was fused to $\alpha_{82}$ and $\alpha_{49}$ (bottom left and right figures, respectively).

Polyacrylamide gel electrophoresis revealed that $\alpha_{82}$ and $\alpha_{49}$ were $>95 \%$ pure, while $\alpha_{23}$ was $\sim 80 \%$ pure (Figure 2). The $\alpha_{23}$ protein was less soluble than the others and was generated in lesser amounts. Yield and solubility were improved by replacing 5 non-conserved hydrophobic amino acids with hydrophilic residues and by growing cells aerobically at low temperatures. $\alpha_{82}$ contained about $4 \mathrm{Fe}$ 's and $0.2 \mathrm{Ni}$ 's per mol (relative uncertainties of metal analyses are estimated at $\pm 25 \%$ ).

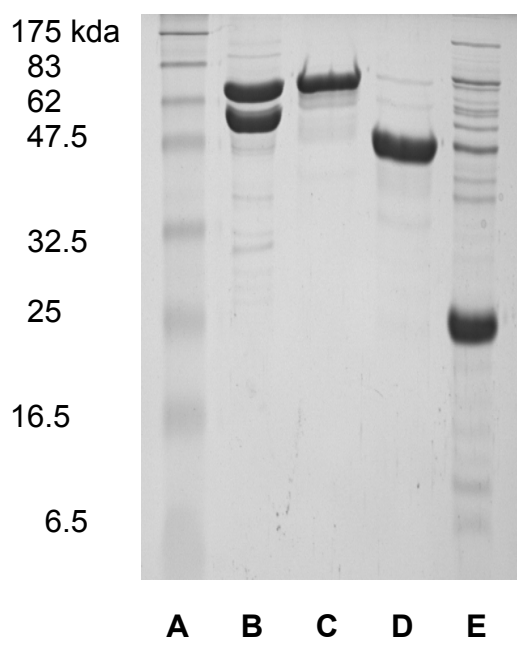

Figure 2. SDS-PAGE Gel (12\%) of A) standard marker, B) recombinant ACS, C) $\alpha_{82}$, D) $\alpha_{49}$, E) $\alpha_{23}$.

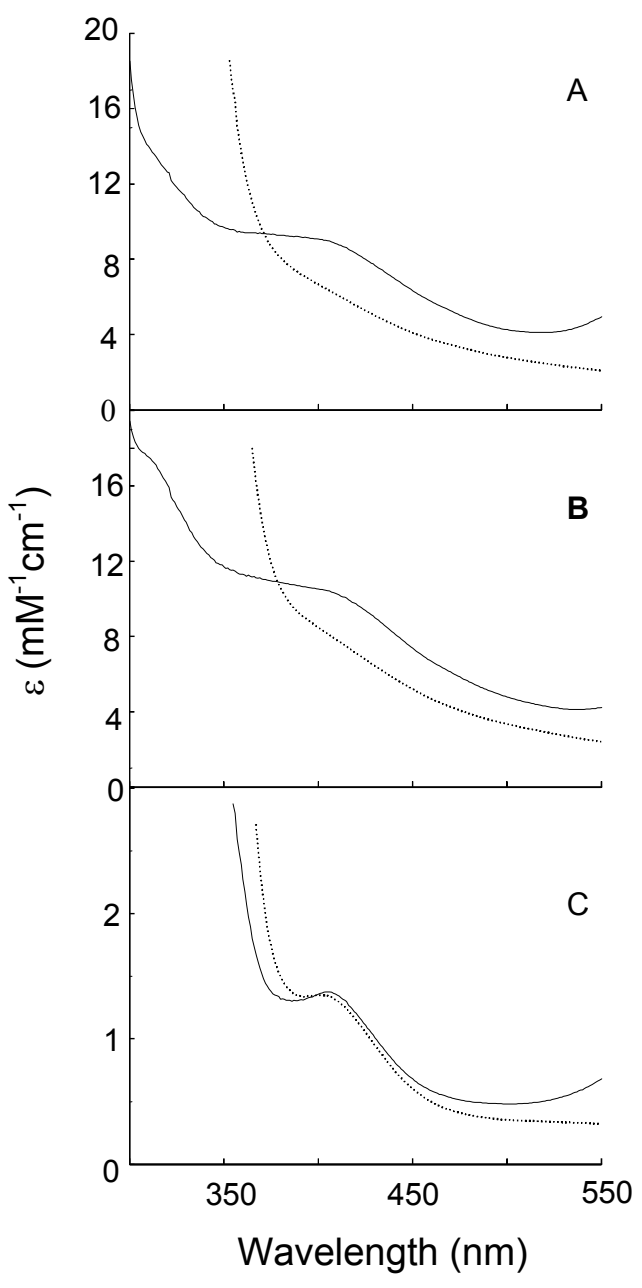


Figure 3. Electronic Absorption Spectra of A) $\alpha_{82}$, B) $\alpha_{49}$, C) $\alpha_{23}$ (solid line, oxidized with thionin; dotted line, reduced with dithionite). Intensity in the $550 \mathrm{~nm}$ region of spectra from oxidized samples is due to thionin.

When oxidized with thionin, $\alpha_{82}$ exhibited an electronic absorption spectrum (Figure 3A) consisting of a broad shoulder in the $400 \mathrm{~nm}$ region, indicative of $\left[\mathrm{Fe}_{4} \mathrm{~S}_{4}\right]^{2+}$ clusters. Spectral intensity declined when $\alpha_{82}$ was treated with dithionite, indicating that some or all of the clusters in solution were reduced to the $\left[\mathrm{Fe}_{4} \mathrm{~S}_{4}\right]^{1+}$ state. These properties are similar to those of isolated $\alpha$ subunit obtained by physically separating it from native ACS using SDS and electrophoresis. ${ }^{34}$ When treated with CO and dithionite, $\alpha_{82}$ was EPR-silent at $130 \mathrm{~K}$. However, after incubation with $\mathrm{NiCl}_{2}, \mathrm{CO}$ /dithionite-treated protein exhibited a signal (Figure 4A) with g-values and spin intensity $(0.2 \mathrm{spin} / \mathrm{mol})$ typical of the $\mathrm{A}_{\mathrm{red}} \mathrm{CO}$ state of the A-cluster in native ACS. ${ }^{33}$ This indicates that the cluster housed in activated $\alpha_{82}$ can also exist in the $\mathrm{A}_{\text {red }}-\mathrm{CO}$ state. The absence of the $\mathrm{NiFeC}$ signal in unactivated samples suggests that the analytically detected $\mathrm{Ni}$ ions are associated with nonlabile A-clusters. Surprisingly, $\alpha_{82}$ catalyzed the synthesis of acetyl-CoA using $\mathrm{CH}_{3}-\mathrm{Co}^{3+} \mathrm{FeSP}, \mathrm{CoA}$, and $\mathrm{CO}$ as substrates (Figure 5). The rate maximized at $0.3 \mu \mathrm{mol} / \mathrm{min} \cdot \mathrm{mg}$ at $80 \mu \mathrm{M} \mathrm{CO}$, about 10-fold slower than native ACS under similar conditions. ${ }^{47}$ A detailed comparison of the catalytic properties of $\alpha_{82}$ and native ACS is underway.

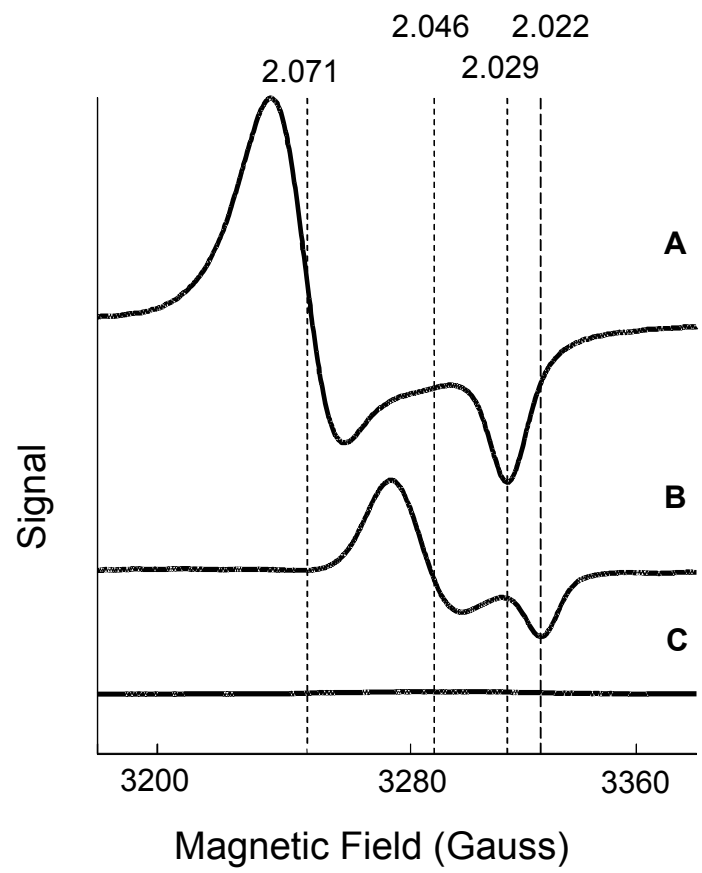

Figure 4. $130 \mathrm{~K}$ X-Band EPR spectra of activated: A) $\alpha_{82}(7.6 \mathrm{mg} / \mathrm{mL})$; B) $\alpha_{49}(3.9 \mathrm{mg} / \mathrm{mL})$; and C) $\alpha_{23}(4.4 \mathrm{mg} / \mathrm{mL})$. Conditions: microwave power, $80 \mathrm{~mW}$; microwave frequency, $9.42 \mathrm{GHz}$; modulation frequency, $100 \mathrm{KHz}$; modulation amplitude, $11.8 \mathrm{G}$; sweep time, $164 \mathrm{~s}$; time constant, $328 \mathrm{~ms}$.

$\alpha_{49}$ contained about $4 \mathrm{Fe}$ 's and $0.5 \mathrm{Ni}$ 's per mol, and exhibited electronic absorption spectra in the oxidized and reduced states similar to those of $\alpha_{82}$ (Figure 3B). Ni-activated $\alpha_{49}$ that was reduced with dithionite and exposed to $\mathrm{CO}$ exhibited a signal (Figure 4B) with g-values similar to that of the so-called "pseudo$\mathrm{NiFeC}$ " signal from $\alpha$ subunits that had been isolated using the SDS/electrophoresis method. ${ }^{49,50}$ The intensity of this signal quantified to $0.05 \mathrm{spin} / \mathrm{mol}$. The sample exhibited no acetyl-CoA synthase activity. These spectroscopic properties imply that the A-cluster derivative present in $\alpha_{49}$ can be reduced and bound with
CO similar to that in $\alpha_{82}$ and native ACS. However, this ability must not be sufficient for catalytic activity.

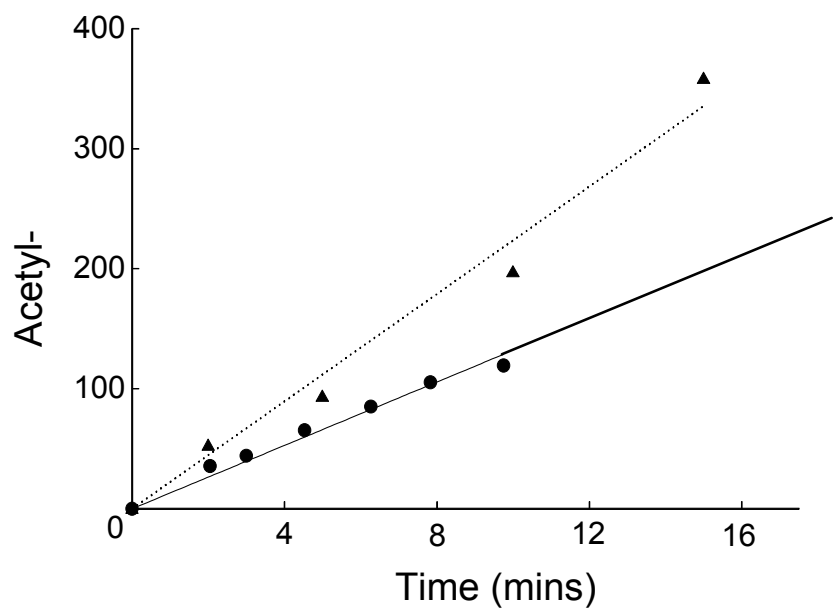

Figure 5. Plot of acetyl-CoA $(\mu \mathrm{M})$ produced by activated $\alpha_{82}$ vs. time in the presence of $(\bullet) 40 \mu \mathrm{M}$ and $(\boldsymbol{\Delta}) 80 \mu \mathrm{M}$ of $\mathrm{CO}$.

Solutions of $\alpha_{23}$ contained $\mathrm{Fe}$ and $\mathrm{Ni}$ quantifying to about 2 Fe's and 2 Ni's per mol. Absorption spectra of thionin-treated and dithionite-treated $\alpha_{23}$ were similar (Figure 3C). Relative to spectra of $\alpha_{82}$ and $\alpha_{49}$, the shape of the $400 \mathrm{~nm}$ shoulder in the spectra of $\alpha_{23}$ was narrower and more resolved. As such, the spectra were more like those of oxidized ferredoxins with $\left[\mathrm{Fe}_{4} \mathrm{~S}_{4}\right]^{2+}$ clusters, ${ }^{51}$ while spectra of $\alpha_{82}$ and $\alpha_{49}$ resembled that from the $\left\{\mathrm{Ni}: \mathrm{Fe}_{4} \mathrm{~S}_{4}\right\}$-containing metallopeptide of Holm and Laplaza. ${ }^{16}$ Ni-activated-and-dithionite/CO-treated $\alpha_{23}$ was EPR silent (Figure 4C), and the protein did not catalyze the synthesis of acetyl-CoA. Overall, these results suggest that $\alpha_{23}$ contains redox-inactive $\left[\mathrm{Fe}_{4} \mathrm{~S}_{4}\right]^{2+}$ clusters with about half occupancy. The unusually high $\mathrm{Ni}$ content detected analytically may reflect adventitiously bound $\mathrm{Ni}$ ions, possibly leached from the $\mathrm{Ni}$ affinity column used in purification. There is no evidence that these ions were associated with the cluster. In any event, the cluster in $\alpha_{23}$ is less like the A-cluster than those in $\alpha_{82}$ and $\alpha_{49}$.

Biosynthesis and Characterization of Chimeric Metalloproteins. The genetics-based method used here to truncate metalloproteins can also be used to construct new proteins with multiple metal centers. In principle, this could be accomplished by fusing two or more gene-fragments, each of which encode a metallocenter "module". The second aim of this study was to assess the feasibility of this. We chose to fuse the gene encoding the ferredoxin from $C$. vinosum to those of $\alpha_{82}$ and $\alpha_{49}$. This $10 \mathrm{kda}$ electron-transfer protein contains 2 $\left[\mathrm{Fe}_{4} \mathrm{~S}_{4}\right]^{2+/ 1+}$ clusters. Its gene has been cloned and overexpressed in $E$. coli ${ }^{45}$ making it ideal for these studies.

Chimeric proteins $\alpha_{82}$-Fd and $\alpha_{49}$-Fd were prepared as described above. They were $\sim 95 \%$ pure, including a second band that migrated slightly faster than the major bands (Supporting information). The origin of these bands is uncertain, though they may reflect instability of the recombinant proteins.

Dithionite-reduced recombinant Fd exhibited an EPR signal indistinguishable from that previously published (Figure 7A) ${ }^{52}$ However, the corresponding spectrum of $\alpha_{49}-\mathrm{Fd}$ (Figure 7B) exhibited a substantially different signal, with rhombic symmetry and $\mathrm{g}=2.134,2.062$, and $1.989\left(\mathrm{~g}_{\mathrm{av}}=2.06\right)$. Upon Ni-activation and exposure to $\mathrm{CO}, \alpha_{49}-\mathrm{Fd}$ exhibited a complex spectrum 
consisting of the $\mathrm{g}_{\mathrm{av}}=2.06$ signal and a near-axial signal characteristic of the pNiFeC signal (Figure 7C). The intensity of the former signal was reduced relative to that of Figure 7B. An equivalent solution of $\alpha_{49}$ mixed with isolated $\mathrm{Fd}$ exhibited signals that were the simple sum of each protein (spectrum not shown), indicating that the novel spectral features observed with the chimera resulted from fusing the two proteins. Dithionitereduced recombinant $\alpha_{82}-\mathrm{Fd}$ also exhibited the $\mathrm{g}_{\mathrm{av}}=2.06$ signal (Figure 7D). Ni-activated dithionite-reduced/CO-treated $\alpha_{82}-\mathrm{Fd}$ exhibited the $\mathrm{NiFeC}$ signal, analogous to the spectrum of $\mathrm{Ni}-$ activated/dithionite-reduced/CO-treated $\alpha_{49}-\mathrm{Fd}$, but only a hint of the $\mathrm{g}_{\mathrm{av}}=2.06$ signal (Figure 7E). We do not understand all aspects of these spectra, but it is clear that the magnetic properties of the metal centers in the chimeras are not simply the sums of those from the individual components, suggesting magnetic interactions of some sort.

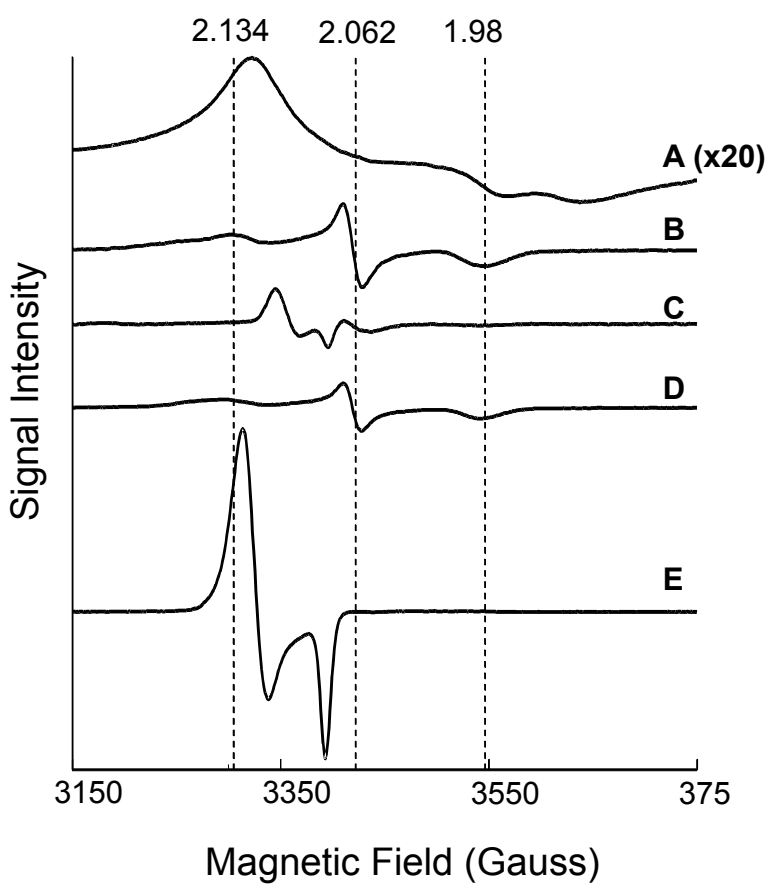

Figure 7. $10 \mathrm{~K} \mathrm{X}$-Band EPR Spectra of A) dithionite-reduced Fd (1.4 $\mathrm{mg} / \mathrm{mL})$, B) dithionite-reduced $\alpha_{49}-\mathrm{Fd}(16 \mathrm{mg} / \mathrm{mL})$, C) dithionitereduced/CO-treated activated $\left.\alpha_{49}-\mathrm{Fd}(8.0 \mathrm{mg} / \mathrm{mL}), \mathrm{D}\right)$ dithionite-reduced $\alpha_{82}-\mathrm{Fd}(27 \mathrm{mg} / \mathrm{mL})$, E) dithionite-reduced/CO-treated activated $\alpha_{82}-\mathrm{Fd}(22$ $\mathrm{mg} / \mathrm{mL}$ ). Conditions: microwave power, $0.05 \mathrm{~mW}$; microwave frequency, $9.61 \mathrm{GHz}$; modulation frequency, $100 \mathrm{KHz}$; modulation amplitude, 11.8 G; sweep time, $164 \mathrm{~s}$; time constant, $328 \mathrm{~ms}$.

\section{Discussion}

Metalloenzymes that contain multiple metal sites are generally difficult to study, in that spectroscopic features from those centers tend to overlap. Moreover, catalytic, substrate-binding and redox properties tend to be more complex and difficult to interpret than for mono-metal-centered enzymes. One advantage of genetically truncating complex metalloenzymes into metallocenter "modules", as we have done here, is that such modules are simpler and easier to study. The truncated proteins generated in this study should be useful for disentangling the catalytic mechanism of the native enzyme, as well as its spectroscopic, redox, and CO-binding properties. A second advantage to genetic truncation methods is that gene-fragments encoding different metallocenter modules can be fused to generate new chimeric metalloproteins. Thus, gene truncation methods can be used to

decompose/simplify complex naturally occurring metalloenzymes as well as to generate new and potentially interesting complex metalloenzymes. The broad objective of this study was to illustrate these advantages using acetyl-CoA synthase as the complex system, the A-cluster as the metallocenter module, and the ferredoxin from $C$. vinosum as second module to be combined with the first to generate new metalloproteins. This study also highlights a disadvantage of genetic truncation, namely it is not a rational design approach, at least in our hands; the complexities of tertiary and quaternary protein structures are overwhelming.

Our study also has specific implications for the mechanism of acetyl-CoA synthase. The ability of the isolated $\alpha$ subunit to catalyze the synthesis of acetyl-CoA, using $\mathrm{CO}$ as a substrate, demonstrates that the $\beta$ subunit is not required for this activity under this condition. Rather, the $\beta$ subunit appears responsible for $\mathrm{CO}_{2} / \mathrm{CO}$ redox catalysis and for delivering $\mathrm{CO}$ to the A-cluster during the catalytic synthesis of acetyl-CoA. Consequently, the recently proposed mechanism in which an electron is shuttled between the A-cluster and the C-cluster during each catalytic cycle ${ }^{53}$ does not appear correct in this respect.

Our results also eliminate the possibility that the heterogeneity described above arises from the quaternary organization of the native tetramer or from an association with the $\beta$ subunit. The low spin intensity of the $\mathrm{NiFeC}$ signal of $\alpha_{82}$ indicates that populations of isolated $\alpha$ subunits are heterogeneous in the same manner and to the same degree as native ACS. Heterogeneity must be somehow intrinsic to a population of $\alpha$ subunits, independent of the host organism expression system.

It is not clear why $\alpha_{82}$ was catalytically active, while the $\alpha_{49}$ protein was inactive. In one sense, the $30 \mathrm{kda}$ region that differentiates the two proteins must be responsible for this difference. However, such a region is not required for catalysis in other ACS's, suggesting that it may not be directly involved in the catalytic mechanism but may simply stabilize the subunit in the required conformation. Deletion of this region may have perturbed the A-cluster or the region surrounding it (as evidenced by the pseudo-NiFeC signal of $\alpha_{49}$ spectra), and this may have destroyed the activity. The perturbation that yielded the $\mathrm{pNiFeC}$ signal in a previous study had been attributed to the loss of the $\beta$ subunit, ${ }^{50}$ but our results suggest that the perturbation arose from damage incurred during isolation. Also, the presence of a pNiFeC-like signal does not unambiguously indicate inactivity. ACS from Methanosarcina thermophila exhibits an EPR signal resembling the $\mathrm{pNiFeC}$ signal of $C$. thermoaceticum ACS, but this enzyme catalyzes the cleavage of acetyl-CoA. ${ }^{54}$

The magnetic/electronic and catalytic properties of the chimeric proteins need to be investigated further, and our inclusion of them illustrates the potential utility of genetically fusing metallocenter modules. Combining modules in combinatorial fashion might generate large numbers of potentially useful metalloproteins and enzymes. Such an approach is complementary to "rational design" or "redesign" methods of generating new metalloproteins. We hope that future employment of all these approaches will yield a synergy out of which novel metalloenzymes with interesting and useful catalytic properties can be generated at increasing rates.

Acknowledgement. We thank Professor Jean-Marc Moulis from CEA/Grenoble for the vector pCVFD10. This work was 
supported by the Department of Energy (DE-FG03-01ER15177) and the National Institutes of Health (GM46441).

Supporting Information: Figure of Gel. This material is available free of charge via the Internet at http://pubs.acs.org.

REFERENCES

(1) Bryson, J. W.; Betz, S. F.; Lu, H. S.; Suich, D. J.; Zhou, H. X.; O'Neil, K. T.; DeGrado, W. F. Science 1995, 270, 935-941.

(2) Gibney, B. R.; Mulholland, S. E.; Rabanal, F.; Dutton, P. L. Proc. Natl. Acad. Sci. USA. 1996, 93, 15041-15046.

(3) Mulholland, S. E.; Gibney, B. R.; Rabanal, F.; Dutton, P. L. J. Am. Chem. Soc. 1998, 120, 10296-10302.

(4) DeGrado, W. F.; Summa, C. M.; Pavone, V.; Nastri, F.; Lombardi, A. Аnпu. Rev. Biochem. 1999, 68, 779-819.

(5) Pasternak, A.; Kaplan, S.; Lear, J. D.; DeGrado, W. F. Protein Science 2001, 10, 958-969.

(6) Robertson, D. E.; Farid, R. S.; Moser, C. C.; Mulholland, S. E.; Pidikiti, R.; Lear, J. D.; Wand, A. J.; DeGrado, W. F.; Dutton, P. L. Nature 1994, $368,425-432$

(7) Rabanal, F.; DeGrado, W. F.; Dutton, P. L. J. Am. Chem. Soc. 1996, 118, $473-474$.

(8) Gibney, B. R.; Isogai, Y.; Rabanal, F.; Reddy, K. S.; Grosset, A. M.; Moser, C. C.; Dutton, P. L. Biochemistry 2000, 39, 11041-11049.

(9) Handel, T.; DeGrado, W. F. J. Am. Chem. Soc. 1990, 112, 6710-6711.

(10) Regan, L; Clarke, N. D. Biochemistry 1990, 29, 10878-10883.

(11) Regan, L. Trends Biochem. Sci. 1995, 20, 280-285.

(12) Wallup, G. K.; Imperiali, B. J. Am. Chem. Soc. 1996, 118, 3053-3054

(13) Struthers, M. D.; Cheng, R.P. Imperiali, B. J. Am. Chem. Soc. 1996, 118 , 3073-3081.

(14) Torrado, A.; Wallup, G. K.; Imperiali, B. J. Am. Chem. Soc. 1998, 120 609-610.

(15) Cheng, R. P.; Fisher, S.L.; Imperiali, B. J. Am. Chem. Soc. 1998, 120 $11349-11356$

(16) Laplaza, C. E. Holm, R. H. J. Am. Chem. Soc 2001, 123, 10255-10264.

(17) Tucci, G. C.; Holm, R. H. J. Am. Chem. Soc. 1995, 117, 6489-6496.

(18) Schleber, P. J.; Mandimutsira, B. S.; Riordan, C. G.; Liable-Sands, L. M.; Incarvito, C. D.; Rheingold, A. L. J. Am. Chem. Soc. 2001, 123, 331-332.

(19) Sellmann, D.; Häussinger, D.; Knoch, F.; Moll, M. J. Am. Chem. Soc. 1996, $118,5368-5374$

(20) Osterloh, F.; Saak, W.; Pohl, S. J. Am. Chem. Soc. 1997, 119, 5648-5656.

(21) Hellinga, H. W.; Richards, F. M. J. Mol. Biol. 1991, 222, 763-785.

(22) Coldren, C. D.; Hellinga, H. W.; Caradonna, J. P. Proc. Natl. Acad. Sci. USA. 1997, 94, 6635-6640.

(23) Benson, D. E.; Wisz, M. S.; Liu, W.; Hellinga, H. W. Biochemistry 1998 37, 7070-7076.

(24) Pinto, A. L.; Hellinga, H. W.; Caradonna, J. P. Proc. Natl. Acad. Sci. USA. 1997, 94, 5562-5567.

(25) Sigman, J. A.; Kwok, B. C.; Lu, Y. J. Am. Chem. Soc. 2000, 122, 81928196.

(26) Sigman, J. A.; Kwok, B. C.; Gengenbach, A.; Lu, Y. J. Am. Chem. Soc. 1999, $121,8949-8950$.

(27) Lu, Y.; Berry, S. M.; Pfister, T. D. Chem. Rev. 2001, 101, 3047-3080.

(28) Lindahl, P. A. Biochemistry 2002, 41, in press.

(29) Xia, J.; Sinclair, J. F.; Baldwin, T. O.; Lindahl, P. A. Biochemistry 1996, 35, 1965-1971.

(30) Shin, W.; Lindahl, P.A. Biochemistry 1992, 31, 12870-12875.

(31) Xia, J.; Hu, W.; Popescu, C. V.; Lindahl, P.A; Münck, E. J. Am. Chem. Soc. 1997, 119, 8301-8312

(32) Shin, W.; Lindahl, P.A. J. Am. Chem. Soc. 1992, 114, 9718-9719.

(33) Shin, W.; Anderson, M. E.; Lindahl, P. A. J. Am. Chem. Soc. 1993, 115, $5522-5526$

(34) Xia, J.; Dong, J.; Wang, S.; Scott, R. A; Lindahl, P. A. J. Am. Chem. Soc $1995,117,7065-7070$

(35) Russell, W. K.; Stålhandske, C. M. V.; Xia, J.; Scott, R. A.; Lindahl, P. A. J. Am. Chem. Soc. 1998, 120, 7502-7510.

(36) Barondeau, D. P.; Lindahl, P. A. J. Am. Chem. Soc. 1997, 119, 39593970

(37) Zeghouf, M.; Fontecave, M.; Covès, J.; J. Biol. Chem. 2000, 275, 3765137656.

(38) Zeghouf, M.; Fontecave, M.; Macherel, D.; Covès, J. Biochemistry 1998 , $37,6114-6123$

(39) Matthews, R. G. Acc. Chem. Res. 2001, 34, 681-689.

(40) Lappalainen, P.; Aasa, R.; Malmström, B. G.; Saraste, M.; J. Biol. Chem. 1993, 268, 26416-26421.

(41) Slutter, C.E.; Sanders, D.; Wittung, P.; Malmström, B. G.; Aasa, R.; Richards, J. H.; Gray, H.B.; Fee, J. A.; Biochemistry 1996, 35, 3387 3395.

(42) Bertini, I; Bren, K.L.; Clemente, A.; Fee, J.A.; Gray, H.B.; Luchinat, C. Malmström, B. G.; Richards, J. H.; Sanders, D.; Slutter, C.E. ; J. Am Chem. Soc. 1996, 118, 11658-11659.

(43) Loke, H. -K., Bennett, G. N., Lindahl, P. A. Proc. Natl. Acad. Sci. USA 2000, $97,12530-12535$

(44) Morton, T. A.; Runquist, J. A.; Ragsdale, S. W. Shanmugasundaram, T. Wood, H. G.; Ljungdahl, L. G. J. Biol. Chem. 1991, 266, 23824-23828.

(45) Moulis, J. -M. Biochimica et Biophysica Acta 1996, 1308, 12-14.

(46) Maynard, E. L.; Sewell, C.; Lindahl, P. A. J. Am. Chem. Soc. 2001, 123, 4697-4703.

(47) Maynard, E. L.; Lindahl, P. A. J. Am. Chem. Soc. 1999, 121, 9221-9222.

(48) Lindahl, P. A.; Chang, B. Orig. Life. Evol. Biosph. 2001, 31, 403-434.

(49) Xia, J.; Lindahl, P. A. Biochemistry 1995, 34, 6037-6042.
(50) Xia, J.; Lindahl, P. A. J. Am. Chem. Soc. 1996, 118, 483-484.

(51) Holm, R. H. Accts. of Chem. Approach 1997, 10, 427-434.

(52) Kyritsis, P.; Kümmerle, R.; Huber, J. G.; Gaillard, J.; Guigliarelli, B.; Popescu, C.; Münck, E.; Moulis, J. -C. Biochemistry 1999, 38, 63356345.

(53) Seravalli, J.; Kumar, M.; Ragsdale, S. W. Biochemistry 2002, 41, 18071819

(54) Lu, W. -P.; Jablonski, P. E.; Rasche, M.; Ferry, J. G.; Ragsdale, S. W. J. Biol. Chem. 1994, 269, 9736-9742. 
Authors are required to submit a graphic entry for the Table of Contents (TOC) that, in conjunction with the manuscript title, should give the reader a representative idea of one of the following: A key structure, reaction, equation, concept, or theorem, etc., that is discussed in the manuscript. The TOC graphic should be no wider than $4.72 \mathrm{in}$. (12 cm) and no taller than $1.81 \mathrm{in.}(4.6 \mathrm{~cm})$.

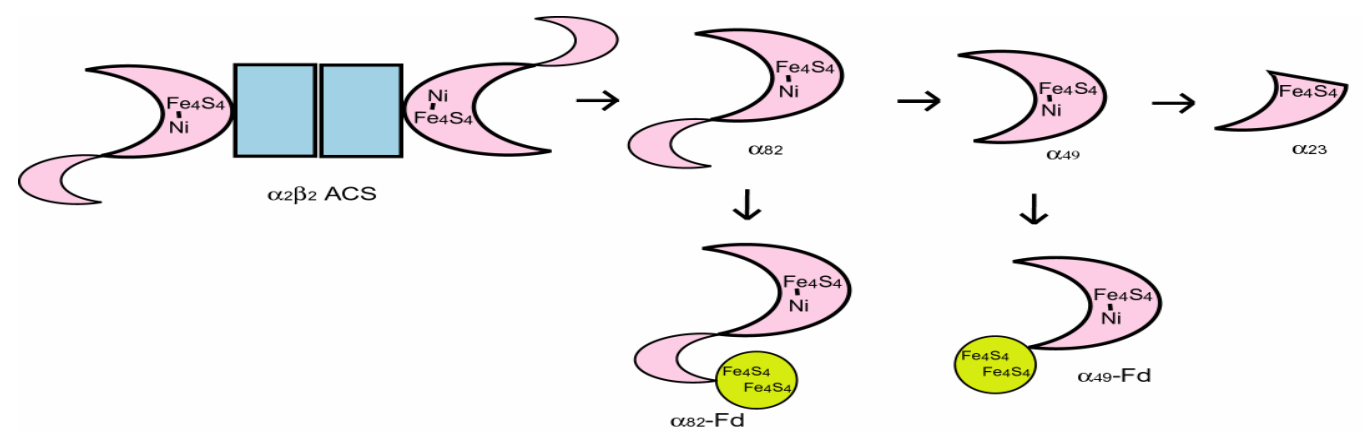

Abstract: In this study, a genetics-based method is used to truncate acetyl-coenzyme A synthase from Clostridium thermoaceticum (ACS), an $\alpha_{2} \beta_{2}$ tetrameric $310 \mathrm{kda}$ bifunctional enzyme. ACS catalyzes the reversible reduction of $\mathrm{CO}_{2}$ to $\mathrm{CO}$ and the synthesis of acetyl-CoA from $\mathrm{CO}$ (or $\mathrm{CO}_{2}$ in the presence of low-potential reductants), CoA, and a methyl group bound to a corrinoid-iron sulfur protein (CoFeSP). ACS contains 7 metal-sulfur clusters of 4 different types called A, B, C, and D. The $B, C$, and $D$ clusters are located in the $72 \mathrm{kda} \beta$ subunit while the A-cluster, a Ni-X-Fe $\mathrm{S}_{4}$ cluster that serves as the active site for acetyl-CoA synthase activity, is located in the $82 \mathrm{kda} \alpha$ subunit. The extent to which the essential properties of the cluster, including catalytic, redox, spectroscopic, and substrate-binding properties, were retained as ACS was progressively truncated was determined. Acetyl-CoA synthase catalytic activity remained when the entire $\beta$ subunit was removed, as long as $\mathrm{CO}$, rather than $\mathrm{CO}_{2}$ and a low-potential reductant, was used as a substrate. Truncating an $\sim 30 \mathrm{kda}$ region from the $\mathrm{N}$ terminus of the $\alpha$ subunit yielded a 49 kda protein that lacked catalytic activity but exhibited A-cluster-like spectroscopic, redox, and $\mathrm{CO}$ binding properties. Further truncation afforded a $23 \mathrm{kda}$ protein that lacked recognizable A-cluster properties except for UV-vis spectra typical of $\left[\mathrm{Fe}_{4} \mathrm{~S}_{4}\right]^{2+}$ clusters. Two chimeric proteins were constructed by fusing the gene encoding a ferredoxin from Chromatium vinosum to genes encoding the $49 \mathrm{kda}$ and $82 \mathrm{kda}$ fragments of the $\alpha$ subunit. The chimeric proteins exhibited EPR signals that were not the simple sum of the signals from the separate proteins, suggesting magnetic interactions between clusters. This study highlights the potential for using genetics to simplify the study of complex multicentered metalloenzymes and to generate new complex metalloenzymes with interesting properties. 